\title{
A rapid RT-PCR based method for the detection of BCR-ABL translocation
}

Janna Yu Sidorova, Liudmila B Saltykova, Anton A Lyschov, Andrey Yu Zaritskey, Kudrat M Abdulkadyrov, Michail N Blinov

\begin{abstract}
Aims-To optimise a one step reverse transcriptase polymerase chain reaction (RT-PCR) protocol for BCR-ABL chimaera detection.

Methods-Compared with published RTPCR procedures, this novel approach has at least two advantages. First, the same enzyme is used for both reverse transcription and PCR. Second, amplification of the target (BCR-ABL chimaera) and control gene (ABL) is performed simultaneously in the same tube.

Results-On testing 40 chronic myelogenous leukaemia patients and 10 healthy donors there was a specificity for the newly developed technique. In addition, dilution experiments demonstrated that the protocol was highly sensitive.

Conclusions-The suggested one step PCR strategy is a simple and reliable way to reveal BCR-ABL chimaeras.

(F Clin Pathol: Mol Pathol 1997;50:266-268)
\end{abstract}

Keywords: chronic myelogenous leukaemia; reverse transcriptase polymerase chain reaction; BCR-ABL

BCR-ABL translocation $\mathrm{t}(9,22)$ occurs in $95 \%$ of chronic myelogenous leukaemia (CML) cases and in $15-25 \%$ of acute lymphocytic leukaemia (ALL) cases, often resulting in the appearance of the so called Philadelphia (Ph) chromosome. Detection of this alteration plays an important role in the differential diagnosis and monitoring of haematological malignancies. ${ }^{1-4}$ In particular, testing for the translocation allows one to identify the type of haematoblastosis at the time of onset and thus choose the appropriate treatment. Once diagnosed, BCR-ABL translocation can be used as a marker of a malignant clone to monitor the efficacy of treatment and to predict relapse.

For some years, this chromosomal damage has been detected cytogenetically. However, recently, cytogenetic procedures have been extensively replaced by polymerase chain reaction (PCR) based protocols. The advantages of PCR detection of BCR-ABL translocation lie in its high specificity and unique sensitivity ${ }^{5-7}$ : PCR is able to detect the mutated gene even in some cytogenetically normal ( $\mathrm{Ph}$ negative) leukaemic clones and can even detect it in the presence of thousands of normal genomes. Thus, PCR is much more informative than cytogenetics alone as a means of $t(9,22)$ detection.
Many PCR based protocols for the diagnosis $\frac{\bar{m}}{\overparen{D}}$ of the BCR-ABL chimaera have been publi- $\cong$ shed. ${ }^{8-11}$ Most of them include the detection of $\%$ the translocation at the level of the RNA tran- $\overrightarrow{0}$ script. The method usually consists of two $\vec{\overrightarrow{ }}$ steps. The first reaction is that of obtaining $\vec{\omega}$ cDNA from RNA by means of reverse $\bar{\xi}$ transcription (RT). Subsequently, an aliquot of cDNA is transferred to another tube and subjected to the second reaction, that is, PCR in amplification. Two different enzymes are used, namely, reverse transcriptase for the RT step o and Taq polymerase for the PCR.

RT-PCR can be simplified significantly if another thermostable enzyme, namely $T$ th, is $\frac{O}{0}$ used instead. Tth is known to possess both RT and DNA polymerase activity. ${ }^{12}$ Thus, only $\vec{\oplus}$ minimal adjusting of the reaction mixture in the tube is necessary to switch the process from. RT to PCR. Such "one tube" RT-PCR protocols have been developed already for many widely used procedures. ${ }^{13}{ }^{14}$ However, there are no published accounts of the potential benefits of this rapid RT-PCR strategy for the $\varrho$ detection of BCR-ABL translocation.

In this paper, we present a one tube protocol for BCR-ABL chimaera detection. The method is cheap and time saving. Also, the reduction in the numbers of manipulations minimises the risk of contamination. Finally, this modification combines both the specificity and sensitivity of traditional PCR procedures.

\section{Materials and methods}

RNA ISOLATION
White blood cells were pelleted by softo centrifugation and RNA was isolated according to a standard protocol. ${ }^{15}$

\section{PCR CONDITIONS}

Multiplex RT-PCR was used in the study? Detection of the BCR-ABL chimaeric transcripto was performed using the CML A (5'-GGA GCTGCAGATGCTGACCMC-3' (bcr spe-? cific) ${ }^{10}$ and ABL3 (5'-CCATTTT TGGTTT GGGCTTCACACCAT TCC-3' (abl speci- $\stackrel{\circ}{\mathbb{D}}$ fic) ${ }^{9}$ primers. To control the efficiency of PCR, $\stackrel{\odot}{\overparen{D}}$ a 233 base pair abl oncogene fragment was amplified simultaneously in the same tube using primers ${ }^{9}$ ABL2 (5'-CAGCG GCCAGTAG-o̊ CATCTAC TTTG-3') and ABL3.

The first step of the reaction included theo reverse transcription of abl specific sequences.? The RT mixture $(10 \mu \mathrm{l})$ contained $67 \mathrm{mM}$ Tris $\mathrm{HCl}(\mathrm{pH} \mathrm{8.8}), 16.6 \mathrm{mM}\left(\mathrm{NH}_{4}\right)_{2} \mathrm{SO}_{4}, 0.2 \mathrm{mM}$ $\mathrm{MnCl}_{2}, 500 \mathrm{nM}$ ABL3 primer, $0.2 \mathrm{mM}$ dNTPs, $2.5 \%$ glycerol, 2.5 units Tth thermostable polymerase (TET-Z polymerase; 


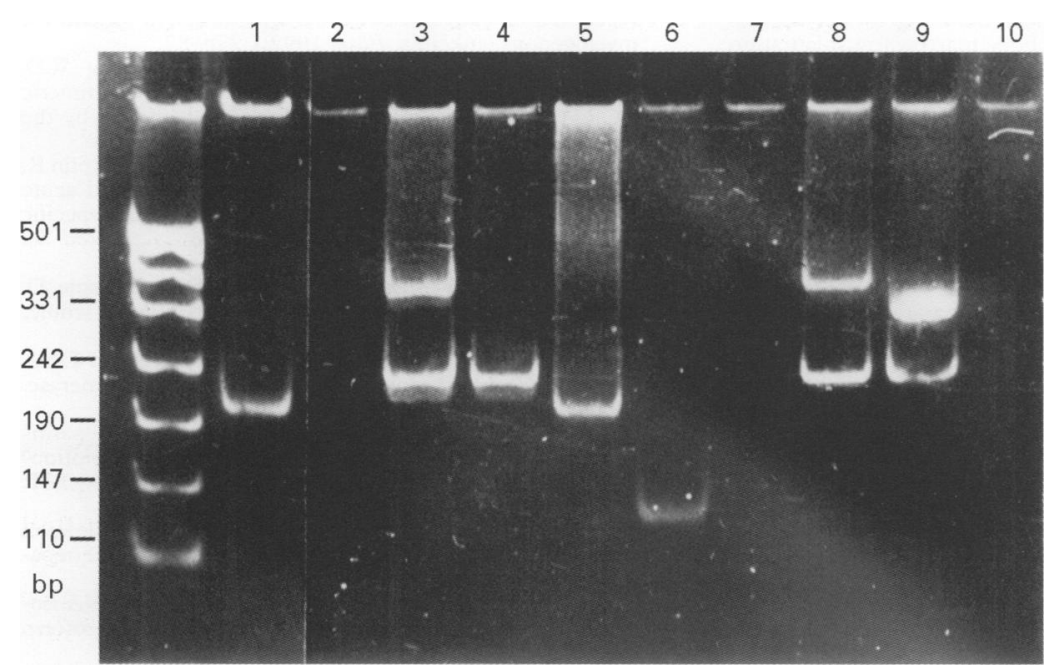

Figure 1 Detection of the BCR-ABL chimaera by different PCR protocols. $R N A$ samples were analysed by means of methods reported previously ${ }^{10}$ (lanes 1, 2, 5, 6, and 7) and the newly developed RT-PCR approach (lanes 3, 4, 8, 9, and 10). Healthy donors yielded no product (lane 2) and a 233 base pair ABL specific product only (lane 4). The b3:a2

$B C R-A B L$ translocation resulted in extra bands of 200 base pairs (standard RT-PCR: lane $1, K-562$ cell line; lane 5, patient 1 ) or 397 base pairs (one tube protocol: lanes 3 and 8, the same RNA samples). The b2:a2 chimaera (patient 2) was recognised by the 125 base pair (lane 6) or 322 base pair (lane 9) additional fragments. Water negative controls are represented in lanes 7 and 10. Molecular weight markers (MspI digested pUC 19 plasmid) are on the left side of the gel.

Biomaster, Moscow, Russia), and 0.1-0.7 $\mu \mathrm{g}$ of total leucocyte RNA. The tubes were overlaid with mineral oil and heated for two minutes at $94^{\circ} \mathrm{C}$ for RNA denaturation. Annealing of the ABL3 primer was performed at $65^{\circ} \mathrm{C}$ for five minutes. The RT reaction was completed by specific synthesis of $\mathrm{cDNA}$ at $70^{\circ} \mathrm{C}$ for $20 \mathrm{~min}-$ utes.

To perform the second step of the reaction, the mixture in the tubes was adjusted for PCR conditions by adding $2 \mu 110 \times$ stock solution comprising: $670 \mathrm{mM}$ Tris $\mathrm{HCl}$ (pH 8.8), $166 \mathrm{mM}\left(\mathrm{NH}_{4}\right)_{2} \mathrm{SO}_{4}, 7.5 \mathrm{mM}$ EGTA, $0.25 \%$ (vol/vol) Tween 20, 25\% glycerol, $2 \mathrm{mM}$ dNTP, $20 \mathrm{mM} \mathrm{MgC1}_{2}, 500 \mathrm{nM}$ ABL2, $500 \mathrm{nM}$ CML A, $2 \mathrm{mM}$ dNTP, and sterile distilled water up to $20 \mu 1$. PCR was started by cDNA denaturation $\left(94^{\circ} \mathrm{C}\right.$ for two minutes). The thermal cycler settings for the initial 10 cycles were: $94^{\circ} \mathrm{C}$ for 50 seconds (denaturation), and $65^{\circ} \mathrm{C}$ for one minute (annealing +

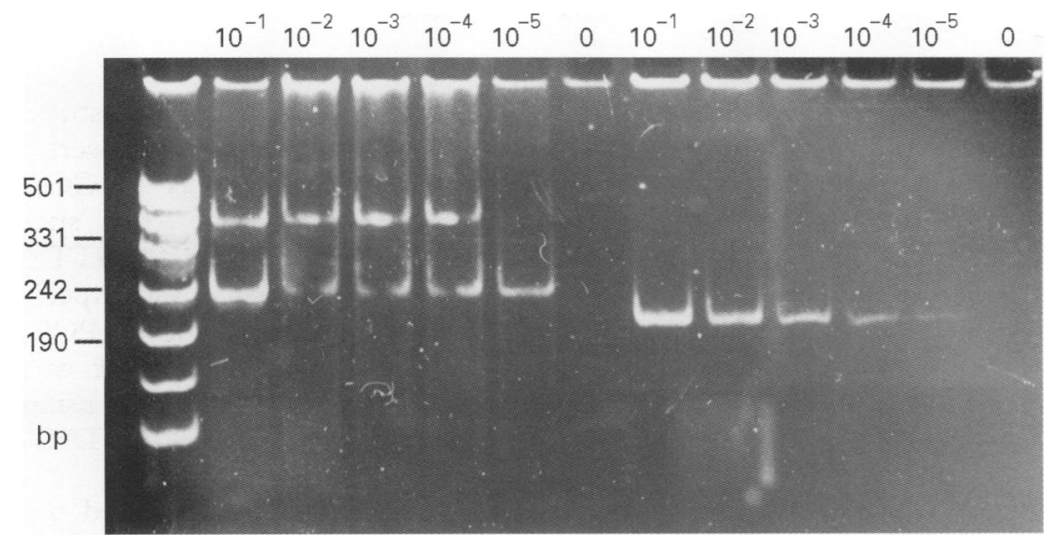

Figure 2 Comparison of the sensitivity of RT-PCR protocols. Serially diluted samples of total $R N A$ from $K-562$ cells were mixed with different amounts of leucocyte $R N A$ from healthy donors and subjected to RT-PCR analysis. Numbers at the top represent the ratio between concentrations of K-562 and normal RNA. Results of the one tube protocol are shown on the left of the figure; results of the basic method are shown on the right. Details of the fragments are given in the legend for fig 1. Msp digested pUC19 plasmid DNA was used as a marker. synthesis). The next 25 cycles consisted of: 40 seconds at $94^{\circ} \mathrm{C}$ (denaturation), 50 seconds at $55^{\circ} \mathrm{C}$ (annealing), and 60 seconds at $72^{\circ} \mathrm{C}$ (synthesis). The reaction was completed by a final elongation at $72^{\circ} \mathrm{C}$ for seven minutes. The PCR products were separated electrophoretically on a $6 \%$ polyacrylamide gel and visualised by routine ethidium bromide staining.

\section{Results}

Forty CML patients (38 $\mathrm{Ph}$ positive and two $\mathrm{Ph}$ negative) and 10 healthy donors were chosen for the comparison of the specificity of standard and novel PCR based methods for BCR-ABL chimaera detection. RNA samples were subjected, in parallel, to standard RT-PCR ${ }^{10}$ and to one tube RT-PCR tests. As shown in fig 1 , both PCR variants gave the same results, revealing the translocation in all CML patients but not in control samples; the b3:a2 translocation variant was observed in 28 cases, whereas the remaining $12 \mathrm{CML}$ patients carried the b2:a2 type of abnormality.

The sensitivity of the new approach was tested by dilution experiments. K-562, a $\mathrm{Ph}$ positive chronic leukaemia cell line, was used as a source of the BCR-ABL chimaeric transcript. Total RNA from these cells was mixed in different proportions with RNA from healthy donors and subjected to PCR analysis. Whereas the standard RT-PCR ${ }^{10}$ revealed the translocation at a dilution of 1 in $10^{-5}$, our technique was limited to 1 in $10^{-4}$ (fig 2).

\section{Discussion}

In this study, we have adapted one tube $T$ th based RT-PCR methodology ${ }^{12}$ for the detection of BCR-ABL translocation. Unlike published procedures for the detection of BCR-ABL chimaeras, both steps of this test were performed in the same Eppendorf tube and required the same enzyme.

The simplification of BCR-ABL diagnosis is unlikely to increase the frequency of false results. In our hands, both rapid and standard RT-PCR methodologies revealed the translocation in all CML cases, indicating the lack of false negative detection. The method appears, therefore, to be most useful in the detection of the mutation. However, our procedure demonstrated an approximately 10-fold decrease in sensitivity in dilution experiments. Although the estimated threshold (one mutated gene copy in 10000 normals) of the one tube protocol remains sufficient for monitoring purposes, the reliable detection of residual malignant cells in peripheral blood or bone marrow might need to rely on the more laborious standard RT-PCR protocol. Conversely, the reduction in the numbers of manipulations and reagents decreases the probability of false positive results caused by contamination.

In conclusion, we have described a rapid RT-PCR procedure which is advantageous in the routine detection of $B C R-A B L$ chimaeras owing to its simplicity and reliability. This method is recommended as a laboratory test for CML diagnosis and assessment. 
1 Delage R, Soiffer RJ, Dear K, Ritz J. Clinical significance of BCR-ABL gene rearrangement detected by polymerase chain reaction after allogenic bone marrow transplantation in chronic myelogenous leukemia. Blood 1991;78:2759-

2 Daley GQ, Van Etten RA, Baltimore D. Induction of chronic myelogenous leukemia by the $\mathrm{P} 210 \mathrm{bcr} / \mathrm{abl}$ gene of the Philadelphia chromosome. Science 1990;247:824-30.

3 Sawyers CL. Molecular consequences of the BCR-ABL translocation in chronic myelogenous leukemia. Leuk Lymphoma 1993;11:101-3.

4 Butturini A, Gale RP. Detecting minimal residual leukemia. Cancer Genet Cytogenet 1991,52:19-26.

5 Miyamura K, Takeo T, Kataoka T, Tahara T, TanDnoto M, Saito $H$. Detection of minimal residual disease in Philadelphia chromosome positive acute lymphoblastic leukemia: rationale for bone marrow transplantation from the polymerase chain reaction point of view. Leuk Lymphoma 1993;11:181-9.

6 Fey MF, Kulozik AK, Hansen-Hagge THE, Tobler A. The polymerase chain reaction: a new tool for the detection of minimal residual disease in haematological malignancies. Eur $\mathcal{F}$ Cancer 1991;27:89-94.

7 Negrin RS, Blume KG. The use of the polymerase chain reaction for the detection of minimal residual malignant disease. Blood 1991;2:255-8.

8 Roth MS, Antin JH, Ash R, Terry VH, Gotlieb M, Silver SM, et al. Prognostic significance of Philadelphia chromosome-positive cells detected by polymerase chain reaction after allogenic bone marrow transplant for chronic myelogenous leukemia. Blood 1992;1:276-82.

9 Maurer J, Janssen JW, van Denderen J, Ludwig WD, Maurer J, Janssen JW, van Denderen J, Ludwig WD,
Aydemir U, Heinze B, et al. Detection of chimeric Aydemir U, Heinze B, et al. Detection of chimeric
BCR-ABL genes in acute lymphoblastic leukemia by the polymerase chain reaction. Lancet 1991;337:1055-8.

10 Kawasaki ES, Clark SS, Coyne MY, Smith SD, Champlin R, White ON, et al. Diagnosis of chronic myeloid and acute 으 lymphocytic leukemias by detection of leukemia-specific mRNA sequences amplified in vitro. Proc Natl Acad Sci USA 1988;85:5698-702.

11 Kolbe T, Guddy K, Brodsky D, Marks DL, Gillespie D. Detection of BCR-ABL fusion mRNA in samples of whole, $\overline{\bar{ज}}$
unfractionated blood. Leuk Res 1994;18:465-8.

12 Myers TW, Gelfand DH. Reverse transcription and DNA amplification by Thermus thermophilus DNA polymerase. Biochemistry 1991;30:7661-6.

13 Young KK, Resnick RM, Myers TW. Detection of hepatitis $C$ virus RNA by a combined reverse transcription- $\mathbb{D}$ polymerase chain reaction assay. $\mathcal{F}$ Clin Microbiol 1993;31: 응 882-6.

of AMPLICOR hepatitis $C$ virus test for detection of hepa- $\overrightarrow{0}$ titis C virus RNA. $\mathcal{F}$ Clin Microbiol 1995;33:1775-8.

15 Chomczyuski P, Sacchi N. Single-step method of RNA isolation by acid guanidinium thiocyanate-phenol-chloroform $\vec{\omega}$ extraction Anal Biochem 1987;162:156-9. 